\title{
AVALIAÇÃO DA QUALIDADE DA ÁGUA DA SUB-BACIA DO RIO ORICÓ, APA DO PRATIGI
}

\author{
Simão Mascarenhas Fernandes ${ }^{1}$; Taise Bonfim de Jesus ${ }^{2}$ \\ 1. Bolsista FAPESB, Graduando em Agronomia, Universidade Estadual de Feira de Santana, e-mail: \\ simao_mascarenhas@hotmail.com \\ 2. Orientador, Departamento de Ciências Exatas, Universidade Estadual de Feira de Santana, e-mail: \\ taisebj@hotmail.com
}

PALAVRAS-CHAVE: Parâmetros físico-químicos; geoquímica; monitoramento ambiental.

\section{INTRODUÇÃOO}

A água é um recurso indispensável para a vida na terra, é um bem de domínio público e recurso natural limitado. A qualidade da água é de imensa importância, e saber as informações sobre a mesma é relevante para a compreensão dos processos ambientais. A atividade humana é diretamente responsável no que se diz respeito à manutenção do meio ambiente, em especial o corpo hídrico, uma vez que esse vem sofrendo bastante nos últimos anos (Parron et al., 2011). Boa parte da contaminação de rios e nascentes se dá pela proximidade destes ao perímetro urbano e/ou de atividades desenvolvidas pelo homem, a falta de estrutura de saneamento em localidades, o uso desencadeado de defensivos agrícolas e rejeitos descartados pelas indústrias de maneira indevida são alguns dos colaboradores para a contaminação em massa de corpos hídricos em todo mundo. As consequências desses atos causam um alto impacto ambiental, uma vez que todo aquele ecossistema é atingido, e nele estão a flora e fauna presentes. A contaminação do corpo hídrico pode deixar a água e a biota existente inapropriada para consumo, por isso é importante o monitoramento para verificação dos níveis de substâncias orgânicas e inorgânicas não desejáveis em alto nível e sedimentos no corpo hídrico, uma vez que a consumo de água ou organismos contaminados, pode causar sérios danos tanto ao homem ou animal que vier a realizar o consumo. A Área de Proteção Ambiental (APA) do Pratigi está localizada no Baixo Sul do estado da Bahia abrangendo os municípios de Ituberá, Nilo Peçanha, Piraí do Norte e Ibirapitanga, possui Clima Tropical chuvoso de floresta (OCT,2004), nela está o Rio Oricó, importante rio da região responsável pelo abastecimento de milhares de moradores, o mesmo pertence à baía do Rio de Contas e tem como afluentes o Rio dos Gatos, Buri, Burizinho e Rio Pitio. Por se tratar de um rio de grande importância para a região, estudos são necessários para que se possa monitorar a qualidade de todo o corpo hídrico, pela relevância que o mesmo tem e o quanto vem sofrendo com poluição e estiagem nos últimos anos. O local foi escolhido para o desenvolvimento do presente projeto, que visa à realização de atividades que vão desde a coleta em campo de amostras de água do rio, até a análise e tratamentos de dados dos resultados encontrados, assim sendo possível a interpretação geoquímica perante os resultados e pesquisas realizadas. 


\section{MATERIAL E MÉTODOS}

A Área de Proteção Ambiental de Pratigi encontra-se no domínio do bioma de mata atlântica, localiza-se no baixo sul do estado da Bahia. A área total estimada é de 85686 hectares, situada entre as coordenadas $8460000 \mathrm{~S}$ e $8500000 \mathrm{~S}$ de latitude e $505000 \mathrm{~W}$ e $448000 \mathrm{~W}$. Os pontos de coleta de água foram escolhidos de acordo com as condições de acesso e de atividades ao entorno, totalizando seis pontos. As coletas aconteceram em novembro de 2017. Os parâmetros físico-químicos medidos in situ foram, temperatura, turbidez, salinidade, $\mathrm{pH}$, condutividade elétrica e sólidos dissolvidos totais. Após as coletas as amostras foram encaminhadas para o Laboratório de Geoquímica e Catálise Ambiental (UEFS) para preparação e posteriormente levados para o Laboratório de Saneamento (LABOTEC) da UEFS para a análise da Demanda Bioquímica de Oxigênio. Foi utilizado um aparelho GPS para medir as coordenadas geográficas nos locais de cada coleta.

\section{RESULTADOS E/OU DISCUSSÃO}

Tabela 1. Parâmetros físico-químicos nas águas da sub-bacia do Rio Oricó, BA.

\begin{tabular}{|c|c|c|c|c|c|c|c|}
\hline Parâmetro & Ponto 1 & Ponto 2 & Ponto 3 & Ponto 4 & Ponto 5 & Ponto 6 & $\begin{array}{c}\text { CONAMA } \\
357 / 05\end{array}$ \\
\hline $\begin{array}{l}\text { Salinidade } \\
\text { (ppm) }\end{array}$ & 60,78 & 58,04 & 54,93 & 45,32 & 42,80 & 43,08 & $\begin{array}{c}\text { Não } \\
\text { aplicável }\end{array}$ \\
\hline $\begin{array}{c}\text { Turbidez } \\
\text { (NTU) }\end{array}$ & 24.23 & 24.33 & 21.00 & 21.00 & 17.10 & 9.87 & $<100$ \\
\hline $\begin{array}{l}\text { Condutividade } \\
(\mu \mathrm{s} / \mathrm{cm})\end{array}$ & 112.9 & 105.6 & 99.54 & 79.77 & 75.20 & 74.50 & $\begin{array}{c}\text { Não } \\
\text { aplicável }\end{array}$ \\
\hline $\mathrm{pH}$ & 6.69 & 7.00 & 6.71 & 6.97 & 6.63 & 6.94 & 6 a 9 \\
\hline SDT (ppm) & 59.72 & 55.87 & 52.58 & 41.50 & 39.70 & 39.37 & $<500$ \\
\hline $\begin{array}{c}\text { Temperatura } \\
{ }^{\circ} \mathrm{C}\end{array}$ & 24.9 & 28.1 & 26.9 & 26.1 & 26.0 & 26.8 & $\begin{array}{c}\text { Não } \\
\text { aplicável }\end{array}$ \\
\hline $\begin{array}{c}\mathrm{DBO} 0-40 \\
\mathrm{mg} / \mathrm{L} \mathrm{O}_{2}\end{array}$ & 4.0 & 2.0 & 10.0 & 6.0 & 3.0 & 4.0 & $<5$ \\
\hline
\end{tabular}

Legenda: $\mathrm{DBO}=$ Demanda Bioquímica de Oxigênio. SDT= Sólidos Dissolvidos Totais.

Dos parâmetros analisados e apresentados na tabela 1, os que possuem limites estabelecidos pelo CONAMA são: pH, Turbidez, Sólidos Dissolvidos Totais e Demanda Bioquímica de Oxigênio.

Os valores do $\mathrm{pH}$ apresentaram pouca variação, ficando entre levemente ácido e levemente básico, nos pontos, todos os valores estavam dentro dos limites permitidos pela legislação vigente. Atividades antrópicas podem afetar o valor do $\mathrm{pH}$, esgotos lançados sem tratamento, seja de natureza doméstica ou industrial, porém, mesmo constatado o despejo de esgotos domésticos diretamente no Rio, os valores não ficaram fora do estabelecido pela CONAMA 357/05.

Os valores de Sólidos Dissolvidos Totais também estavam de acordo com o valor estabelecido pela CONAMA 357/05 em todos os pontos de coleta. As principais fontes de SDT em águas receptoras são de uso agrícola, residencial, esgotos, águas industriais 
e estações de tratamento. As substâncias dissolvidas podem conter íons de natureza orgânica ou inorgânica, que em concentrações excessivas podem causar danos ao ecossistema aquático (Parron, 2011), influenciando diretamente o parâmetro Turbidez, onde os valores os valores não foram excedidos quando comparados a resolução CONAMA 357/05 em nenhum dos pontos de coleta. A turbidez indica o grau de atenuação que a luz sofre ao atravessar a água. Esta atenuação ocorre pela absorção e espalhamento da luz causada pelos sólidos em suspensão (silte, areia, argila, algas, detritos, etc.) e mesmo na presença de esgotos despejados de maneira incorreta os valores apresentaram-se dentro do estipulado pela CONAMA 357/05.

Em relação a Demanda Bioquímica de Oxigênio valores adequados foram observados nos pontos 1, 2, 5 e 6 . Os pontos 3 e 4 apresentaram valores acima do estipulado pela Resolução CONAMA 357/05. Os valores obtidos no ponto 3 foram o dobro $\left(10 \mathrm{mg} / \mathrm{L}^{-1}\right)$ do valor máximo permitido pelo CONAMA. Não por coincidência, os pontos de coletas que apresentam valores fora do padrão estão próximos a perímetros urbanos, com deposição de esgoto doméstico sem algum tratamento. A DBO expressa à quantidade necessária de oxigênio para que a matéria orgânica presente na água seja oxidada através de decomposição microbiana. O lançamento de cargas com muita matéria orgânica pode provocar o aumento da DBO, ao exemplo de esgotos domésticos. Altos valores desse parâmetro podem causar diminuição do oxigênio dissolvido, implicando na mortalidade de peixes e outros organismos aquáticos.

Os parâmetros Temperatura, Salinidade e Condutividade Elétrica não possuem valores de referência na Resolução CONAMA 357/05, porém possuem papel importante nas reações que ocorrem no corpo hídrico e podem ser comparados com os valores encontrados nos rios próximos, ao exemplo do Rio Juliana. A temperatura variou entre $24,9^{\circ} \mathrm{C}$ e $28,1^{\circ} \mathrm{C}$, com média de $26,45^{\circ} \mathrm{C}$ entre os pontos ficando próximo dos $25,47^{\circ} \mathrm{C}$ de médio constatado por Moreira (2014) nos corpos d'água da bacia do Rio Juliana (Bacia da APA Pratigi, BA). Lançamentos de efluentes podem alterar a temperatura da água, que interfere diretamente na reprodução de algumas espécies. A Salinidade variou de 60,78 ppm a 42,80 ppm, onde seu valor máximo foi alcançado no ponto 1 e o menor valor no ponto 5, apresentou uma média de 50,12 ppm, e está relacionada a condutividade elétrica.

A condutividade elétrica pode variar de acordo com a temperatura e a concentração total de substâncias ionizadas dissolvidas, aumenta proporcionalmente ao aumento de sólidos dissolvidos totais, isso é perceptível em todos os pontos de coleta. Em comparação aos dados obtidos por Moreira (2014), os valores constatados no Rio Oricó foram superiores, apresentando média de $89,66 \mu \mathrm{s} / \mathrm{cm}$, quando os dados encontrados da Bacia do Rio Juliana tiveram médias de 48,98 $\mu \mathrm{s} / \mathrm{cm}$.

O estudo permitiu constatar que apenas um dos parâmetros avaliados nas águas do Rio Oricó encontra-se com valores fora do padrão estabelecido pela RESOLUÇÃO CONAMA 357/05, os demais parâmetros apresentaram valores dentro do padrão estabelecido pelo CONAMA. A explicação para valores fora da faixa pode ser dada por conta da quantidade de ações antrópicas pontuais que são exercidas ao longo das margens do rio. Fica evidente a necessidade de novas abordagens no rio, com coletas de água em períodos diferentes (seco e chuvoso), para devida comparação de dados 
gerando um estudo mais abrangente do seu atual estado de degradação. Além disso, faz-se necessário fazer as análises de metais para uma abordagem macro, em relação aos parâmetros físico-químicos da sub-bacia em estudo.

\section{REFERENCIAS}

MONTEIRO, V.P.; PINHEIRO, J.C.V. 2004. Critério para implantação de tecnologias de suprimentos de água potável em municípios cearenses afetados pelo alto teor de sal. Revista de Economia Rural.

BRASIL, Conselho Nacional do Meio Ambiente (CONAMA). Resolução CONAMA n.357, de 17 de março de 2005. Dispõe sobre a classificação dos corpos de água e diretrizes para seu enquadramento, bem como estabelece as condições e padrões de lançamento de afluentes e dá outras providências.

MOREIRA, P,R.; JESUS. Monitoramento da qualidade dos corpos aquáticos da APA do Pratigi. Relatório final do Programa Institucional de Bolsa de Iniciação Científica. Universidade Estadual de Feira de Santana, 2014.

PARRON, L. M.; MUNIZ, D. H. F.; PEREIRA, C. M. Manual de rocedimentos de amostragem e análise físico-química da água. EMBRAPA, 2011.

D. C. C. RENOVATO; C. P. S. SENA e M. M. F. SILVA, Análise de parâmetros físico-químicos das águas da barragem pública da cidade de Pau dos Ferros $(\mathrm{RN})-\mathrm{pH}$, Cor, Turbidez, acidez, alcalinidade, condutividade, cloreto e salinidade

ORGANIZAÇÃO DE CONSERVAÇÃO DA TERRA, disponível em :

<http://www.oct.org.br/apa-do-pratigi/apresentacao/19> acessado em: 20-01-2018 